ISSN 2078-3744. Вісник Львів. ун-ту. Серія мех.-мат. 2020. Випуск 90. С. 92-104

Visnyk of the Lviv Univ. Series Mech. Math. 2020. Issue 90. P. 92-104

http://publications.lnu.edu.ua/bulletins/index.php/mmf

doi: http://dx.doi.org/10.30970/vmm.2020.90.092-104

\title{
CLOSE-TO-CONVEXITY OF POLYNOMIAL SOLUTIONS OF A DIFFERENTIAL EQUATION OF THE SECOND ORDER WITH POLYNOMIAL COEFFICIENTS OF THE SECOND DEGREE
}

\section{Myroslav SHEREMETA, Yuriy TRUKHAN}

\author{
Ivan Franko National University of Lviv, \\ Universytetska Str., 1, 79000, Lviv, Ukraine \\ e-mails:m.m.sheremeta@gmail.com, \\ yurkotrukhan@gmail.com
}

An analytic univalent in $\mathbb{D}=\{z:|z|<1\}$ function $f$ is said to be convex if $f(\mathbb{D})$ is a convex domain and is said to be close-to-convex if there exists a convex in $\mathbb{D}$ function $\Phi$ such that $\operatorname{Re}\left(f^{\prime}(z) / \Phi^{\prime}(z)\right)>0(z \in \mathbb{D})$. We indicate conditions on real parameters $\beta_{0}, \beta_{1}, \gamma_{0}, \gamma_{1}, \gamma_{2}$ and $\alpha_{0}, \alpha_{1}, \alpha_{2}$ of the differential equation

$$
z^{2} w^{\prime \prime}+\left(\beta_{0} z^{2}+\beta_{1} z\right) w^{\prime}+\left(\gamma_{0} z^{2}+\gamma_{1} z+\gamma_{2}\right) w=\alpha_{0} z^{2}+\alpha_{1} z+\alpha_{2},
$$

under which this equation has a polynomial solution

$$
f(z)=\sum_{n=0}^{p} f_{n} z^{n}(\operatorname{deg} f=p \geq 2)
$$

close-to-convex in $\mathbb{D}$ together with all its derivatives $f^{(j)}(1 \leq j \leq p-1)$.

Key words: linear non-homogeneous differential equation of the second order, polynomial coefficient, polynomial solution, close-to-convex function.

\section{INTRODUCTION AND AUXILIARY RESULTS}

An analytic univalent in $\mathbb{D}=\{z:|z|<1\}$ function

$$
f(z)=\sum_{n=0}^{\infty} f_{n} z^{n}
$$

is said to be convex if $f(\mathbb{D})$ is a convex domain. It is well known [1, p. 203] (see also [2. p. 8]) that the condition $\operatorname{Re}\left\{1+z f^{\prime \prime}(z) / f^{\prime}(z)\right\}>0(z \in \mathbb{D})$ is necessary and sufficient for the convexity of $f$. A function $f$ is said to be close-to-convex in $\mathbb{D}$ (W. Kaplan [3, see also [1, p. 583], [2, p. 11]) if there exists a convex in $\mathbb{D}$ function $\Phi$ such that

2020 Mathematics Subject Classification: 34M05, 30B10, 30C45

(C) Sheremeta, M., Trukhan, Yu., 2020 
$\operatorname{Re}\left(f^{\prime}(z) / \Phi^{\prime}(z)\right)>0(z \in \mathbb{D})$. Any close-to-convex function $f$ has a characteristic property that the complement $G$ of the domain $f(\mathbb{D})$ can be filled with rays which start from $\partial G$ and lie in $G$. Every close-to-convex in $\mathbb{D}$ function $f$ is univalent in $\mathbb{D}$ and, therefore, $f^{\prime}(0) \neq 0$. Hence it follows that any function $f$ is close-to-convex in $\mathbb{D}$ if and only if the function $g(z)=z+\sum_{n=2}^{\infty} g_{n} z^{n}$ is close-to-convex in $\mathbb{D}$, where $g_{n}=f_{n} / f_{1}$.

S. M. Shah $\left[4\right.$ indicated conditions on real parameters $\beta_{0}, \beta_{1}, \gamma_{0}, \gamma_{1}, \gamma_{2}$ of the differential equation

$$
z^{2} w^{\prime \prime}+\left(\beta_{0} z^{2}+\beta_{1} z\right) w^{\prime}+\left(\gamma_{0} z^{2}+\gamma_{1} z+\gamma_{2}\right) w=0
$$

under which there exists an entire transcendental solution (1) such that $f$ and all its derivatives are close-to-convex in $\mathbb{D}$. The investigations are continued in the papers $5-10$, but in all of these papers the case of polynomial solutions of $\sqrt{2}$ was not investigated. In the papers $[11-14$ properties of entire solutions of a linear differential equation of $n$ th order with polynomial coefficients of $n$-th degree are investigated. Some results from these papers are published also in monograph [2].

Here we consider a differential equation

$$
z^{2} w^{\prime \prime}+\left(\beta_{0} z^{2}+\beta_{1} z\right) w^{\prime}+\left(\gamma_{0} z^{2}+\gamma_{1} z+\gamma_{2}\right) w=\alpha_{0} z^{2}+\alpha_{1} z+\alpha_{2}
$$

with real parameters and study the existence and closeness-to-convexity of its polynomial solutions.

At first we remark that a function (1) is a solution of the differential equation (3) if and only if

$$
\begin{array}{r}
\sum_{n=2}^{\infty} n(n-1) f_{n} z^{n}+\beta_{0} \sum_{n=2}^{\infty}(n-1) f_{n-1} z^{n}+\gamma_{0} \sum_{n=2}^{\infty} f_{n-2} z^{n}+ \\
+\beta_{1} \sum_{n=1}^{\infty} n f_{n} z^{n}+\gamma_{1} \sum_{n=1}^{\infty} f_{n-1} z^{n}+\gamma_{2} \sum_{n=0}^{\infty} f_{n} z^{n}=\alpha_{0} z^{2}+\alpha_{1} z+\alpha_{2},
\end{array}
$$

i. e.

(4) $\gamma_{2} f_{0}=\alpha_{2}, \quad\left(\beta_{1}+\gamma_{2}\right) f_{1}+\gamma_{1} f_{0}=\alpha_{1}, \quad\left(2+2 \beta_{1}+\gamma_{2}\right) f_{2}+\left(\beta_{0}+\gamma_{1}\right) f_{1}+\gamma_{0} f_{0}=\alpha_{0}$ and for $n \geq 3$

$$
\left(n\left(n+\beta_{1}-1\right)+\gamma_{2}\right) f_{n}+\left(\beta_{0}(n-1)+\gamma_{1}\right) f_{n-1}+\gamma_{0} f_{n-2}=0 .
$$

Clearly, by some condition differential equation (3) may have a linear solution, which obviously is convex function in $\mathbb{D}$. We are going to investigate a solutions of degree $\geq 2$. In this case the following statement is true.

Lemma 1. In order that the polynomial

$$
f(z)=\sum_{n=0}^{p} f_{n} z^{n}, \quad \operatorname{deg} f=p \geq 2,
$$

be a solution of the differential equation (3), it is necessary that $\gamma_{0}=p \beta_{0}+\gamma_{1}=0$. 
Proof. Indeed, for $n=p+2$ from (5) we get

$$
\left((p+2)\left(p+\beta_{1}+1\right)+\gamma_{2}\right) f_{p+2}+\left((p+1) \beta_{0}+\gamma_{1}\right) f_{p+1}+\gamma_{0} f_{p}=0 .
$$

If $f$ has the form (6) then $f_{p+2}=f_{p+1}=0$ and $f_{p} \neq 0$. Therefore, $\gamma_{0}=0$ and from (5) for $n=p+1$ we obtain

$$
\left((p+1)\left(p+\beta_{1}\right)+\gamma_{2}\right) f_{p+1}+\left(p \beta_{0}+\gamma_{1}\right) f_{p}=0
$$

Since $f_{p+1}=0$ and $f_{p} \neq 0$, it follows that $p \beta_{0}+\gamma_{1}=0$. Lemma 1 is proved.

By the condition $\gamma_{0}=p \beta_{0}+\gamma_{1}=0$ from (4) and (5) we get

$$
\gamma_{2} f_{0}=\alpha_{2}, \quad\left(\beta_{1}+\gamma_{2}\right) f_{1}=\alpha_{1}+p \beta_{0} f_{0}, \quad\left(2+2 \beta_{1}+\gamma_{2}\right) f_{2}=\alpha_{0}+(p-1) \beta_{0} f_{1}
$$

and for $3 \leq n \leq p$

$$
\left(n\left(n+\beta_{1}-1\right)+\gamma_{2}\right) f_{n}=(p-n+1) \beta_{0} f_{n-1} .
$$

We remark that the condition $\gamma_{0}=p \beta_{0}+\gamma_{1}=0$ is not sufficient in order that a solution of differential equation (3) has the form (6). Indeed, although in view of (8) we have

$$
\left((p+3)\left(p+\beta_{1}+2\right)+\gamma_{2}\right) f_{p+3}=0
$$

it does not follow from here that $f_{p+3}=0$, since $(p+3)\left(p+\beta_{1}+2\right)+\gamma_{2}$ can be equal to zero. Therefore, further we assume that

$$
n\left(n+\beta_{1}-1\right)+\gamma_{2} \neq 0, \quad 3 \leq n \leq p .
$$

This condition allows us to rewrite the equality (8) in the form

$$
f_{n}=\frac{(p-n+1) \beta_{0}}{n\left(n+\beta_{1}-1\right)+\gamma_{2}} f_{n-1}, \quad n \geq 3,
$$

whence it follows that $f_{p}=0$, if $\beta_{0}=0$. Therefore, further we assume also that $\beta_{0} \neq 0$.

To study the closeness-to-convexity of the polynomial (6), we will use the following criterion of Alexander [15, 16] (see also [2, p. 11]).

Lemma 2. If

$$
1 \geq 2 g_{2} \geq 3 g_{3} \geq \cdots \geq p g_{p}>0
$$

then the polynomial $g(z)=\sum_{n=0}^{p} g_{n} z^{n}$ is close-to-convex in $\mathbb{D}$.

In view of (4) and (5) it is clear that the existence of a close-to-convex solution (6) of differential equation (3) depends on the equality to zero of the parameter $\gamma_{2}$. Therefore, we will consider two cases $\gamma_{2} \neq 0$ and $\gamma_{2}=0$.

\section{Closeness-to-Convexity PRovided $\gamma_{2} \neq 0$}

From the first equality of (7) it follows that $f_{0}=\alpha_{2} / \gamma_{2}$, and the second equality of (7) implies

$$
\left(\beta_{1}+\gamma_{2}\right) f_{1}=\alpha_{1}+p \beta_{0} \alpha_{2} / \gamma_{2} \text {. }
$$

Since the condition $f_{1} \neq 0$ is necessary for a closeness-to-convexity of $f$, from the last equality it follows that either $\beta_{1}+\gamma_{2} \neq 0$ and $\alpha_{1}+p \beta_{0} \alpha_{2} / \gamma_{2} \neq 0$ or

$$
\beta_{1}+\gamma_{2}=\alpha_{1}+p \beta_{0} \alpha_{2} / \gamma_{2}=0 \text {. }
$$


In the first case we have $f_{1}=\frac{\alpha_{1} \gamma_{2}+p \beta_{0} \alpha_{2}}{\gamma_{2}\left(\beta_{1}+\gamma_{2}\right)}$, and if $2+2 \beta_{1}+\gamma_{2} \neq 0$ from the third equality (7) we obtain

$$
f_{2}=\frac{(p-1) \beta_{0}\left(\alpha_{1} \gamma_{2}+p \beta_{0} \alpha_{2}\right)+\alpha_{0} \gamma_{2}\left(\beta_{1}+\gamma_{2}\right)}{\gamma_{2}\left(\beta_{1}+\gamma_{2}\right)\left(2+2 \beta_{1}+\gamma_{2}\right)} .
$$

Using these equalities and equality $(9)$ we prove the following theorem.

Theorem 1. Let $p \geq 3, \gamma_{2} \neq 0, \gamma_{0}=p \beta_{0}+\gamma_{1}=0, \beta_{1}+\gamma_{2} \neq 0, \alpha_{1} \gamma_{2}+p \beta_{0} \alpha_{2} \neq 0$ and

$$
0<\frac{(p-1) \beta_{0}\left(\alpha_{1} \gamma_{2}+p \beta_{0} \alpha_{2}\right)+\alpha_{0} \gamma_{2}\left(\beta_{1}+\gamma_{2}\right)}{\left(\gamma_{2} \alpha_{1}+p \beta_{0} \alpha_{2}\right)\left(2+2 \beta_{1}+\gamma_{2}\right)} \leq \frac{1}{2} .
$$

If for all $3 \leq n \leq p$

$$
0<\frac{(p-n+1) \beta_{0}}{n\left(n+\beta_{1}-1\right)+\gamma_{2}} \leq \frac{n-1}{n}
$$

then differential equation $(3)$ has a close-to-convex in $\mathbb{D}$ polynomial solution

$$
\begin{aligned}
f(z)=\frac{\alpha_{2}}{\gamma_{2}} & +\frac{\alpha_{1} \gamma_{2}+p \beta_{0} \alpha_{2}}{\gamma_{2}\left(\beta_{1}+\gamma_{2}\right)} z+ \\
& +\frac{(p-1) \beta_{0}\left(\alpha_{1} \gamma_{2}+p \beta_{0} \alpha_{2}\right)+\alpha_{0} \gamma_{2}\left(\beta_{1}+\gamma_{2}\right)}{\gamma_{2}\left(\beta_{1}+\gamma_{2}\right)\left(2+2 \beta_{1}+\gamma_{2}\right)} z^{2}+\sum_{n=3}^{p} f_{n} z^{n}
\end{aligned}
$$

where the coefficients $f_{n}$ satisfy $(9)$.

If $\beta_{0}>0,2+\beta_{1}>0$ and either $\gamma_{2}>0$ and $(p-2) \beta_{0} \leq 2+\beta_{1}$ or $-3\left(2+\beta_{1}\right)<\gamma_{2}<0$ and $3(p-2) \beta_{0} \leq 3\left(2+\beta_{1}\right)+\gamma_{2}$ then differential equation (3) has a polynomial solution (12) close-to-convex in $\mathbb{D}$ together with all its derivatives $f^{(j)}(1 \leq j \leq p-1)$.

Proof. Let $g(z)=z+\sum_{n=2}^{p} g_{n} z^{n}$, where $g_{n}=f_{n} / f_{1}$. In view of (9), (10) and (11) $f_{2} / f_{1}>0$ and $f_{n} / f_{1}>0$ for all $3 \leq n \leq p$, i. e. $g_{n}>0$ for all $2 \leq n \leq p$. From 10 it follows also that $2 g_{2} \leq 1$, and (9) and (11) imply $n g_{n} \leq(n-1) g_{n-1}$ for all $3 \leq n \leq p$. Therefore, by Lemma 2 the function $g$ and, thus, the function $f$ are close-to-convex in $\mathbb{D}$. The first part of Theorem 1 is proved.

Now suppose that the condition

$$
0<\frac{(p-(n+j)+1) \beta_{0}}{(n+j)\left(n+j+\beta_{1}-1\right)+\gamma_{2}} \leq \frac{n-1}{n+j}
$$

holds for some $1 \leq j \leq p-2$ and all $2 \leq n \leq p-j$ and show that the derivative $f^{(j)}$ of function $\sqrt{12}$ is close-to-convex in $\mathbb{D}$.

Indeed, for $1 \leq j \leq p-2$ the derivative

$$
f^{(j)}(z)=j ! f_{j}+(j+1) ! f_{j+1} z+\sum_{n=2}^{p-j}(n+1)(n+2) \ldots(n+j) f_{n+j} z^{n} .
$$

is close-to-convex in $\mathbb{D}$ if and only if the function

$$
g_{j}(z)=z+\sum_{n=2}^{p-j} g_{n, j} z^{n}, \quad g_{n, j}=\frac{(n+1)(n+2) \ldots(n+j) f_{n+j}}{(j+1) ! f_{j+1}},
$$


is close-to-convex in $\mathbb{D}$. For the function $g_{j}$ the inequality $2 g_{2, j} \leq 1$ is equivalent to the inequality

$$
\frac{(p-j-1) \beta_{0}}{(j+2)\left(j+\beta_{1}+1\right)+\gamma_{2}} \leq \frac{1}{j+2}
$$

which follows from the condition (13) with $n=2$. If $3 \leq n \leq p-j$ then the inequality $n g_{n, j} \leq(n-1) g_{n-1, j}$ is equivalent to condition (13). Therefore, by Lemma 2 the function $g_{j}$ and, thus, the function $f^{(j)}$ are close-to-convex in $\mathbb{D}$.

Now suppose that $\beta_{0}>0,2+\beta_{1}>0$ and $\gamma_{2}>0$. Then condition (11) holds for all $3 \leq n \leq p$ if $\frac{(p-n+1) \beta_{0}}{n\left(n+\beta_{1}-1\right)} \leq \frac{n-1}{n}$, i. e. $\frac{(p-n+1) \beta_{0}}{(n-1)\left(n+\beta_{1}-1\right)} \leq 1$. Since the left part of the last inequality decreases, this inequality holds if $\frac{(p-2) \beta_{0}}{2\left(2+\beta_{1}\right)} \leq 1$, i. e. $(p-2) \beta_{0} \leq 2+\beta_{1}$. Similarly, condition (13) holds for all $1 \leq j \leq p-2$ and $2 \leq n \leq p-j$ if $\frac{(p-(n+j)+1) \beta_{0}}{(n-1)\left(n+j+\beta_{1}-1\right)} \leq 1$ and the last inequality is true if $\frac{(p-2) \beta_{0}}{2+\beta_{1}} \leq 1$, i. e. $(p-2) \beta_{0} \leq 2\left(2+\beta_{1}\right)$.

Finally, let $\beta_{0}>0,2+\beta_{1}>0$ and $\gamma_{2}<0$. Then for all $3 \leq n \leq p$

$$
\frac{(p-n+1) \beta_{0}}{n\left(n+\beta_{1}-1\right)+\gamma_{2}}=\frac{(p-n+1) \beta_{0}}{n\left(n+\beta_{1}-1-\left|\gamma_{2}\right| / n\right)} \leq \frac{(p-n+1) \beta_{0}}{n\left(n+\beta_{1}-1-\left|\gamma_{2}\right| / 3\right)} .
$$

Therefore, 11] holds for all $3 \leq n \leq p$ if

$$
\frac{(p-n+1) \beta_{0}}{(n-1)\left(n+\beta_{1}-1-\left|\gamma_{2}\right| / 3\right)} \leq 1,
$$

whence as above it follows that 11) holds for all $3 \leq n \leq p$ if $\frac{(p-2) \beta_{0}}{2\left(2+\beta_{1}+\gamma_{2} / 3\right)} \leq 1$, i. e. $-3\left(2+\beta_{1}\right)<\gamma_{2}<0$ and $\frac{3}{2}(p-2) \beta_{0} \leq 3\left(2+\beta_{1}\right)+\gamma_{2}$. Similarly we prove that condition 13 holds for all $1 \leq j \leq p-2$ and $2 \leq n \leq p-j$ if $\frac{(p-2) \beta_{0}}{2+\beta_{1}+\gamma_{2} / 3} \leq 1$, i. e. $-3\left(2+\beta_{1}\right)<\gamma_{2}$ and $3(p-2) \beta_{0} \leq 3\left(2+\beta_{1}\right)+\gamma_{2}$. Thus, for all $1 \leq j \leq p-2$ the derivative $f^{(j)}$ is close-to-convex in $\mathbb{D}$. Since the derivative $f^{(p-1)}$ is a linear function, the proof of Theorem 1 is complete.

Now we consider the case

$$
\beta_{1}+\gamma_{2}=\alpha_{1}+p \beta_{0} \alpha_{2} / \gamma_{2}=0 .
$$

From the second equality $(7)$ it follows that $f_{1}$ may be arbitrary. If we choose $f_{1}=1$ then under the condition $2+\beta_{1} \neq 0$ in view of the third equality $(7)$ we get

$$
f_{2}=\frac{\alpha_{0}+(p-1) \beta_{0}}{2+\beta_{1}} .
$$

From (8) under the condition $n+\beta_{1} \neq 0$ we obtain

$$
f_{n}=\frac{(p-n+1) \beta_{0}}{(n-1)\left(n+\beta_{1}\right)} f_{n-1}, \quad 3 \leq n \leq p .
$$


Theorem 2. Let $p \geq 3, \gamma_{2} \neq 0, \gamma_{0}=p \beta_{0}+\gamma_{1}=\beta_{1}+\gamma_{2}=\alpha_{1} \gamma_{2}+p \beta_{0} \alpha_{2}=0$ and

$$
0<\frac{\alpha_{0}+(p-1) \beta_{0}}{2+\beta_{1}} \leq \frac{1}{2} \text {. }
$$

If for all $3 \leq n \leq p$

$$
0<\frac{(p-n+1) \beta_{0}}{(n-1)\left(n+\beta_{1}\right)} \leq \frac{n-1}{n}
$$

then differential equation (3) has a close-to-convex in $\mathbb{D}$ polynomial solution

$$
f(z)=\frac{\alpha_{2}}{\gamma_{2}}+z+\frac{\alpha_{0}+(p-1) \beta_{0}}{2+\beta_{1}} z^{2}+\sum_{n=3}^{p} f_{n} z^{n}
$$

where the coefficients $f_{n}$ satisfy (14).

If $\beta_{0}>0,2+\beta_{1}>0$ and $3(p-2) \beta_{0} \leq 2\left(3+\beta_{1}\right)$ then differential equation (3) has polynomial solution (17), which together with its derivatives $f^{(j)}(1 \leq j \leq p-1)$ are close-to-convex in $\mathbb{D}$.

Proof. From (14) and (16) the inequality $f_{n}>0$ follows for all $n$. Condition (15) implies the inequality $2 f_{2} \leq 1$ and condition $(16)$ implies $n f_{n} \leq(n-1) f_{n-1}$ for all $3 \leq n \leq p$. Therefore, by Lemma 2 the function $f$ is close-to-convex in $\mathbb{D}$. The first part of Theorem 2 is proved.

Now we suppose the condition

$$
0<\frac{(p-(n+j)+1) \beta_{0}}{(n+j-1)\left(n+j+\beta_{1}\right)} \leq \frac{n-1}{n+j}
$$

holds for some $1 \leq j \leq p-2$ and all $2 \leq n \leq p-j$. The proof of the closeness-to-convexity of the derivative $f^{(j)}(1 \leq j \leq p-2)$ is the same as the proof in Theorem 1 . Note only that the inequality $2 g_{2, j} \leq 1$ is equivalent to the inequality

$$
\frac{(p-j-1) \beta_{0}}{j+2+\beta_{1}} \leq \frac{j+1}{j+2},
$$

which follows from condition (18) for $n=2$, and the inequality $n g_{n, j} \leq(n-1) g_{n-1, j}$ coincides with condition (18).

Let $\beta_{0}>0$ and $2+\beta_{1}>0$. Since the values

$$
\frac{(p-n+1) \beta_{0}}{n+\beta_{1}}, \quad \frac{n}{(n-1)^{2}}, \quad \frac{n+j}{(n-1)(n+j-1)}
$$

decrease with the increasing of $n$ and the value

$$
\frac{(2+j)(p-j-1) \beta_{0}}{(j+1)\left(j+2+\beta_{1}\right)}
$$

decreases with the increasing of $j$, conditions 16 and 18 hold if $\frac{3(p-2) \beta_{0}}{2\left(3+\beta_{1}\right)} \leq 1$, i. e. $3(p-2) \beta_{0} \leq 2\left(3+\beta_{1}\right)$. Thus, for all $1 \leq j \leq p-2$ the derivative $f^{(j)}$ is close-to-convex in $\mathbb{D}$. Since the derivative $f^{(p-1)}$ is a linear function, the proof of Theorem 2 is complete. 


\section{Closeness-to-Convexity PRovided $\gamma_{2}=0$}

Now (7) implies $\alpha_{2}=0$ and, thus, $f_{0}$ may be arbitrary. If we choose $f_{0}=0$ then from (7) and (9) we get

$$
\beta_{1} f_{1}=\alpha_{1}, \quad 2\left(1+\beta_{1}\right) f_{2}=\alpha_{0}+(p-1) \beta_{0} f_{1},
$$

and for $3 \leq n \leq p$

$$
f_{n}=\frac{(p-n+1) \beta_{0}}{n\left(n+\beta_{1}-1\right)} f_{n-1} .
$$

Since for the close-to-convex function $f_{1} \neq 0$, from the first equality of $\left.\sqrt{19}\right)$ it follows that either $\beta_{1} \neq 0$ and $\alpha_{1} \neq 0$ or $\beta_{1}=\alpha_{1}=0$. In the first of these cases the following theorem holds.

Theorem 3. Let $p \geq 3, \gamma_{2}=\alpha_{2}=\gamma_{0}=\gamma_{1}+p \beta_{0}=0, \beta_{1} \neq 0, \alpha_{1} \neq 0$ and

$$
0<\frac{(p-1) \beta_{0} \alpha_{1}+\alpha_{0} \beta_{1}}{\alpha_{1}\left(1+\beta_{1}\right)} \leq 1
$$

If for all $3 \leq n \leq p$

$$
0<\frac{(p-n+1) \beta_{0}}{(n-1)\left(n+\beta_{1}-1\right)} \leq 1
$$

then differential equation (3) has a close-to-convex in $\mathbb{D}$ polynomial solution

$$
f(z)=\frac{\alpha_{1}}{\beta_{1}} z+\frac{(p-1) \beta_{0} \alpha_{1}+\beta_{1} \alpha_{0}}{2 \beta_{1}\left(1+\beta_{1}\right)} z^{2}+\sum_{n=3}^{p} f_{n} z^{n}
$$

where the coefficients $f_{n}$ satisfy 20 .

If $\beta_{0}>0,2+\beta_{1}>0$ and $(p-2) \beta_{0} \leq 2+\beta_{1}$ then differential equation (3) has a polynomial solution 23 close-to-convex in $\mathbb{D}$ together with its derivatives $f^{(j)}(1 \leq j \leq$ $\leq p-1)$.

Proof. Suppose that the function $g$ is defined as in the proof of Theorem 1 . In view of 20), (21) and (22) $f_{2} / f_{1}>0$ and $f_{n} / f_{1}>0$ for all $3 \leq n \leq p$, i. e. $g_{n}>0$ for all $2 \leq n \leq p$. From (21) it follows also that $2 g_{2} \leq 1$, and (22) and (20) imply $n g_{n} \leq(n-1) g_{n-1}$ for all $3 \leq n \leq p$. Therefore, by Lemma 2 the function $g$ and, thus, the function 23 are close-to-convex in $\mathbb{D}$. The first part of Theorem 3 is proved.

Now we suppose that

$$
0<\frac{(p-(n+j)+1) \beta_{0}}{(n-1)\left(n+j+\beta_{1}-1\right)} \leq 1
$$

holds for some $1 \leq j \leq p-2$ and for all $2 \leq n \leq p-j$. Then the proof of the closeto-convexity of the derivative $f^{(j)}$ is the same as the proof in Theorem 1 . Note only the inequality $2 g_{2, j} \leq 1$ is equivalent to the inequality $\frac{(p-j-1) \beta_{0}}{j+1+\beta_{1}} \leq 1$, which follows from condition (24) for $n=2$, and the inequality $n g_{n, j} \leq(n-1) g_{n-1, j}$ coincides with condition 24). 
It is easy to check that if $\beta_{0}>0,2+\beta_{1}>0$ then condition $(22)$ holds for all $3 \leq n \leq p$ if $\frac{(p-2) \beta_{0}}{2\left(2+\beta_{1}\right)} \leq 1$, and 24 holds for all $1 \leq j \leq p-2$ and all $2 \leq n \leq p-1$ if $\frac{(p-2) \beta_{0}}{2+\beta_{1}} \leq 1$, i.e. $(p-2) \beta_{0} \leq 2+\beta_{1}$. The proof of Theorem 3 is complete.

In the second case the following theorem is true.

Theorem 4. Let $p \geq 3, \gamma_{2}=\alpha_{2}=\gamma_{0}=\gamma_{1}+p \beta_{0}=\beta_{1}=\alpha_{1}=0$ and $0<\alpha_{0}+(p-1) \beta_{0} \leq$ $\leq 1$. If $0<(p-n+1) \beta_{0}<(n-1)^{2}$ for all $3 \leq n \leq p$ then differential equation (3) has a close-to-convex in $\mathbb{D}$ polynomial solution

$$
f(z)=z+\frac{(p-1) \beta_{0}+\alpha_{0}}{2} z^{2}+\sum_{n=3}^{p} f_{n} z^{n}
$$

where the coefficients $f_{n}$ satisfy 20 with $\beta_{1}=0$.

If $0<(p-2) \beta_{0} \leq 2$ then differential equation (3) has polynomial solution (25) close-to-convex in $\mathbb{D}$ together with its derivatives $f^{(j)}(1 \leq j \leq p-1)$.

Proof. From the conditions $0<\alpha_{0}+(p-1) \beta_{0} \leq 1$ and $0<(p-n+1) \beta_{0}<(n-1)^{2}$ for all $3 \geq n \geq p$ in view of 20 with $\beta_{1}=0$ it follows as above that all $f_{n}>0,2 f_{2} \leq 1$ and $n f_{n} \leq(n-1) f_{n-1}$ for all $3 \leq n \leq p$. Therefore, by Lemma 2 the function $(25)$ is close-to-convex in $\mathbb{D}$. The first part of Theorem 4 is proved.

Now we suppose that

$$
0<(p-(n+j)+1) \beta_{0} \leq(n-1)(n+j-1)
$$

for some $1 \leq j \leq p-2$ and all $2 \leq n \leq p-j$. Then the proof of the close-to-convexity of the derivative $f^{(j)}$ is the same as the proof in Theorem 11. Note only the inequality $2 g_{2, j} \leq 1$ is equivalent to the inequality $\frac{(p-j-1) \beta_{0}}{j+1} \leq 1$, which follows from condition

$$
0<(p-(n+j)+1) \beta_{0} \leq(n-1)(n+j-1)
$$

for $n=2$, and the inequality $n g_{n, j} \leq(n-1) g_{n-1, j}$ coincides with this condition. Hence as in the proof of Theorem 3 we get the second part of Theorem 4.

\section{Other Results}

The condition $p \geq 3$ in the proved theorems is not significant. Repeating the proofs of these theorems one can show that the following analogues of these theorems are hold for $p=2$.

Proposition 1. Let $\gamma_{2} \neq 0, \gamma_{0}=2 \beta_{0}+\gamma_{1}=0, \beta_{1}+\gamma_{2} \neq 0, \alpha_{1} \gamma_{2}+2 \beta_{0} \alpha_{2} \neq 0,2+2 \beta_{1}+$ $+\gamma_{2} \neq 0$ and

$$
0<\frac{\beta_{0}\left(\alpha_{1} \gamma_{2}+2 \beta_{0} \alpha_{2}\right)+\alpha_{0} \gamma_{2}\left(\beta_{1}+\gamma_{2}\right)}{\left(\gamma_{2} \alpha_{1}+2 \beta_{0} \alpha_{2}\right)\left(2+2 \beta_{1}+\gamma_{2}\right)} \leq \frac{1}{2} .
$$

Then differential equation (3) has a polynomial solution

$$
f(z)=\frac{\alpha_{2}}{\gamma_{2}}+\frac{\alpha_{1} \gamma_{2}+2 \beta_{0} \alpha_{2}}{\gamma_{2}\left(\beta_{1}+\gamma_{2}\right)} z+\frac{\beta_{0}\left(\alpha_{1} \gamma_{2}+2 \beta_{0} \alpha_{2}\right)+\alpha_{0} \gamma_{2}\left(\beta_{1}+\gamma_{2}\right)}{\gamma_{2}\left(\beta_{1}+\gamma_{2}\right)\left(2+2 \beta_{1}+\gamma_{2}\right)} z^{2}
$$

close-to-convex in $\mathbb{D}$. 
Proposition 2. Let $\gamma_{2} \neq 0, \gamma_{0}=2 \beta_{0}+\gamma_{1}=\beta_{1}+\gamma_{2}=\alpha_{1} \gamma_{2}+2 \beta_{0} \alpha_{2}=0,2+\beta_{1} \neq 0$ and $0<\frac{\alpha_{0}+\beta_{0}}{2+\beta_{1}} \leq \frac{1}{2}$. Then differential equation (3) has a polynomial solution

$$
f(z)=\frac{\alpha_{2}}{\gamma_{2}}+z+\frac{\alpha_{0}+\beta_{0}}{2+\beta_{1}} z^{2}
$$

close-to-convex in $\mathbb{D}$.

Proposition 3. Let $\gamma_{2}=\alpha_{2}=\gamma_{0}=\gamma_{1}+2 \beta_{0}=0, \beta_{1} \neq 0, \alpha_{1} \neq 0,1+\beta_{1} \neq 0$ and $0<\frac{\beta_{0} \alpha_{1}+\alpha_{0} \beta_{1}}{\alpha_{1}\left(1+\beta_{1}\right)} \leq 1$. Then differential equation $(3)$ has a polynomial solution

$$
f(z)=\frac{\alpha_{1}}{\beta_{1}} z+\frac{\beta_{0} \alpha_{1}+\beta_{1} \alpha_{0}}{2 \beta_{1}\left(1+\beta_{1}\right)} z^{2}
$$

close-to-convex in $\mathbb{D}$.

Proposition 4. Let $\gamma_{2}=\alpha_{2}=\gamma_{0}=\gamma_{1}+2 \beta_{0}=\beta_{1}=\alpha_{1}=0$ and $0<\alpha_{0}+\beta_{0} \leq 1$. Then differential equation (3) has a polynomial solution

$$
f(z)=z+\frac{\beta_{0}+\alpha_{0}}{2} z^{2}
$$

close-to-convex in $\mathbb{D}$.

Recall that before obtaining the above results we demanded the fulfillment of conditions (9) and $\beta_{0} \neq 0$. Now suppose that $\beta_{0}=0$. Then by Lemma $2 \gamma_{0}=\gamma_{1}=0$, and thus, from (7) and (8) we get

$$
\gamma_{2} f_{0}=\alpha_{2}, \quad\left(\beta_{1}+\gamma_{2}\right) f_{1}=\alpha_{1}, \quad\left(2+2 \beta_{1}+\gamma_{2}\right) f_{2}=\alpha_{0}
$$

and for $3 \leq n \leq p$

$$
\left(n\left(n+\beta_{1}-1\right)+\gamma_{2}\right) f_{n}=0 .
$$

From (27) it follows that if $p\left(p+\beta_{1}-1\right)+\gamma_{2}=0$ then $f_{p} \neq 0$ may be arbitrary. Two cases are possible: 1) $n\left(n+\beta_{1}-1\right)+\gamma_{2} \neq 0$ for all $3 \leq n \leq p$ and 2) there is $3 \leq p_{1}<p$ such that $p_{1}\left(p_{1}+\beta_{1}-1\right)+\gamma_{2}=0$.

In the first case we have $f_{p-1}=0$ provided $p>3$ and it is impossible to use Alexander's criterion. In the second case we have $p_{1} p=\gamma_{2}$ and $p_{1}+p=1-\beta_{1}$. Therefore, if either $p_{1}>3$ or $p>p_{1}+1$ then again we cannot apply Alexander's criterion. Thus, we can apply Alexander's criterion if either $n\left(n+\beta_{1}-1\right)+\gamma_{2} \neq 0$ for all $3 \leq n \leq p$ and $p=3$ or $p_{1}\left(p_{1}+\beta_{1}-1\right)+\gamma_{2}=0$ for some $3 \leq p_{1}<p$ and $p_{1}=3, p=4$.

Given the possible value of the parameter $\gamma_{2}$, using (26) and choosing $f_{3}=2 f_{2} / 3$, you can prove the following statement.

Proposition 5. Let $\beta_{0}=\gamma_{0}=\gamma_{1}=0, p=3$ and $3\left(2+\beta_{1}\right)+\gamma_{2}=0$. Then:

1) if $\gamma_{2} \neq 0, \gamma_{2} \neq 3$ and $\gamma_{2} \neq 6, \alpha_{1} \neq 0$ and $0<\frac{\alpha_{0}\left(\gamma_{2}-3\right)}{\alpha_{1}\left(\gamma_{2}-6\right)} \leq \frac{1}{4}$ then differential equation (3) has a polynomial solution

$$
f(z)=\frac{\alpha_{2}}{\gamma_{2}}+\frac{3 \alpha_{1}}{2\left(\gamma_{2}-3\right)} z+\frac{3 \alpha_{0}}{\gamma_{2}-6} z^{2}+\frac{2 \alpha_{0}}{\gamma_{2}-6} z^{3}
$$

close-to-convex in $\mathbb{D}$; 
2) if $\gamma_{2}=3, \alpha_{1}=0$ and $-\frac{1}{2} \leq \alpha_{0}<0$ then differential equation (3) has a polynomial solution

$$
f(z)=\alpha_{2} / 3+z-\alpha_{0} z^{2}-2 \alpha_{0} z^{3} / 3
$$

close-to-convex in $\mathbb{D}$

3) if $\gamma_{2}=6, \alpha_{0}=0$ and $\alpha_{1} \neq 0$ then differential equation (3) has a polynomial solution

$$
f(z)=\frac{\alpha_{2}}{6}+\frac{\alpha_{1}}{2} z+\frac{\alpha_{1}}{4} z^{2}+\frac{\alpha_{1}}{6} z^{3}
$$

close-to-convex in $\mathbb{D}$;

4) if $\gamma_{2}=\alpha_{2}=0$ and $0<\alpha_{0} / \alpha_{1} \leq 1 / 2$ then differential equation (3) has a polynomial solution

$$
f(z)=-\alpha_{1} z / 2-\alpha_{0} z^{2} / 2-\alpha_{0} z^{3} / 3
$$

close-to-convex in $\mathbb{D}$.

In the case when $3\left(2+\beta_{1}\right)+\gamma_{2}=0$ and $4\left(3+\beta_{1}\right)+\gamma_{2}=0$ (i. e. $\left.p_{1}=3, p=4\right)$ from (26) we get $f_{0}=\alpha_{2} / 12, f_{1}=\alpha_{1} / 6, f_{2}=\alpha_{0} / 2$, and choosing $f_{3}=\alpha_{0} / 3, f_{4}=\alpha_{0} / 4$ we obtain the following statement.

Proposition 6. If $\gamma_{2}=12, \beta_{0}=\gamma_{0}=\gamma_{1}=0,0<\alpha_{0} / \alpha_{1}<1 / 6$,

$$
3\left(2+\beta_{1}\right)+\gamma_{2}=4\left(3+\beta_{1}\right)+\gamma_{2}=0
$$

then differential equation (3) has a polynomial solution

$$
f(z)=\frac{\alpha_{2}}{12}+\frac{\alpha_{1}}{6} z+\frac{\alpha_{0}}{2} z^{2}+\frac{\alpha_{0}}{3} z^{3}+\frac{\alpha_{0}}{4} z^{4}
$$

close-to-convex in $\mathbb{D}$.

Finally, we remark that polynomial (6) can be close-to-convex in the case when $f_{2}=\cdots=f_{p-1}=0$. Since each starlike function is close-to-convex, it follows from such a lemma.

Lemma 3. If $|\alpha| \leq 1 / p$ then the polynomial $f(z)=z+\alpha z^{p}$ is a starlike function.

Proof. Recall that an analytic univalent in $\mathbb{D}$ function $f(z)=z+\sum_{n=2}^{\infty} f_{n} z^{n}$ is said to be starlike if $f(\mathbb{D})$ is starlike domain with respect to the origin. It is well known [1. p. 202] (see also [2, p. 9]) that the condition $\operatorname{Re}\left\{z f^{\prime}(z) / f(z)\right\}>0(z \in \mathbb{D})$ is necessary and sufficient for the starlikeness of $f$. If $f(z)=z+\alpha z^{p}$ then for $|\alpha| \leq 1 / p$ and $|z|<1$ we have

$$
\operatorname{Re} \frac{z f^{\prime}(z)}{f(z)}=\operatorname{Re}\left\{1+\frac{(p-1) \alpha z^{p-1}}{1+\alpha z^{p-1}}\right\} \geq 1-\left|\frac{(p-1) \alpha z^{p-1}}{1+\alpha z^{p-1}}\right|>1-\frac{(p-1)|\alpha|}{1-|\alpha|} \geq 0,
$$

i. e. the function $f(z)=z+\alpha z^{p}$ starlike and, thus, close-to-convex. Lemma 3 is proved.

Suppose that $\gamma_{2} \neq 0$,

$$
\alpha_{2}=\alpha_{0}+(p-1) \beta_{0}=p\left(p+\beta_{1}-1\right)+\gamma_{2}=0,
$$

$\beta_{1}+\gamma_{2}=\alpha_{1}$ and $n\left(n+\beta_{1}-1\right)+\gamma_{2} \neq 0$ for all $n=1,2, \ldots, p-1$. Then in view of (7) $f_{0}=0, f_{1}=1, f_{2}=0$ and in view of (8) $f_{3}=\cdots=f_{p-1}=0$. Choosing $f_{p}=1 / p$ and using Lemma 3 we get the following statement. 
Proposition 7. If $\gamma_{2} \neq 0$,

$$
\alpha_{2}=\alpha_{0}+(p-1) \beta_{0}=p\left(p+\beta_{1}-1\right)+\gamma_{2}=0
$$

and $n\left(n+\beta_{1}-1\right)+\gamma_{2} \neq 0$ for all $n=1,2, \ldots, p-1$ then differential equation (3) has a polynomial solution $f(z)=z+z^{p} / p$ close-to-convex in $\mathbb{D}$.

\section{REFERENCES}

1. G. M. Golusin, Geometric theory of functions of a complex variable, Amer. Math. Soc., Providence, 1969

2. M. M. Sheremeta, Geometric properties of analytic solutions of differential equations, Publisher I. E. Chyzhykov, Lviv, 2019.

3. W. Kaplan, Close-to-convex schlicht functions, Michigan Math. J. 1 (1952), no. 2, 169-185. DOI: $10.1307 / \mathrm{mmj} / 1028988895$

4. S. M. Shah, Univalence of a function $f$ and its successive derivatives when $f$ satisfies a differential equation, II, J. Math. Anal. Appl. 142 (1989), no. 2, 422-430.

DOI: $10.1016 / 0022-247 \mathrm{X}(89) 90011-5$

5. Z. M. Sheremeta, Close-to-convexity of entire solutions of a differential equation, Mat. Metody Fiz.-Mekh. Polya 42 (1999), no. 3, 31-35 (in Ukrainian).

6. 3. М. Шеремета, О свойствах целых решений одного дифференциалъного уравнения, Дифференц. уравнения 36 (2000), no. 8, 1045-1050; English version: Z. M. Sheremeta, The properties of entire solutions of one differential equation, Differ. Equ. 36 (2000), no. 8, 1155-1161. DOI: 10.1007/BF02754183

7. Z. M. Sheremeta, On entire solutions of a differential equation, Mat. Stud. 14 (2000), no. 1, $54-58$.

8. Z. M. Sheremeta, On the close-to-convexity of entire solutions of a differential equation, Visn. L'viv. Univ., Ser. Mekh.-Mat. 58 (2000), 54-56 (in Ukrainian).

9. З. М. Шеремета, М. Н. Шеремета, Близостъ к выпуклости иелых решений одного дифференциального уравнения, Дифференц. уравнения 38 (2002), no. 4, 477-481; English version: Z. M. Sheremeta and M. N. Sheremeta, Closeness to convexity for entire solutions of a differential equation, Differ. Equ. 38 (2002), no. 4, 496-501. DOI: $10.1023 / \mathrm{A}: 1016355531151$

10. Z. M. Sheremeta and M. M. Sheremeta, Convexity of entire solutions of one differential equation, Mat. Metody Fiz.-Mekh. Polya 47 (2004), no. 2, 186-191 (in Ukrainian).

11. Ya. S. Mahola and M. M. Sheremeta, Properties of entire solutions of a linear differential equation of $n$-th order with polynomial coefficients of $n$-th degree, Mat. Stud. 30 (2008), no. 2, 153-162.

12. Ya. S. Mahola and M. M. Sheremeta, Close-to-convexity of entire solution of a linear differential equation with polynomial coefficients, Visn. L'viv. Univ., Ser. Mekh.-Mat. 70 (2009), 122-127 (in Ukrainian).

13. Я. С. Магола, М. М. Шеремета, Про властивості иілих розв'язків лінійних диферениіалъних рівнлнъ з поліноміалъними коефічієнтами, Мат. методи фіз.мех. поля 53 (2010), no. 4, 62-74: English version: Ya. S. Magola and M. M. Sheremeta, On properties of entire solutions of linear differential equations with polynomial coefficients, J. Math. Sci. (New York) 181 (2012), no. 3, 366-382. DOI: 10.1007/s10958-012-0691-9

14. Ya. S. Mahola, On entire solutions with two-member reccurent formula for Taylor coefficients of linear differential equation, Mat. Stud. 36 (2011), no. 2, 133-141.

15. J. F. Alexander, Functions which map the interior of the unit circle upon simple regions, Ann. Math. (2) 17 (1915), no. 1, 12-22. DOI: 10.2307/2007212. 
16. A. W. Goodman, Univalent function, Vol. II, Mariner Publishing Co., 1983.

Стаття: надійшла до редколегї 12.08.2020

доопращвована 17.08.2020

прийнята до друку 17.11.2021

\section{БЛИЗЬКІСТЬ ДО ОПУКЛОСТІ МНОГОЧЛЕННИХ РОЗВ'ЯЗКІВ ДИФЕРЕНЦІАЛЬНОГО РІВНЯННЯ ДРУГОГО ПОРЯДКУ З МНОГОЧЛЕННИМИ КОЕФІЦІЕНТАМИ ДРУГОГО СТЕПЕНЯ}

\section{Мирослав ШЕРЕМЕТА, Юрій ТРУХАН}

Лъвівсъкий націоналъний університет імені Івана Франка, вул. Університетсъка, 1, 79000, Лъвів

e-mail:m.m.sheremeta@gmail.com,yurkotrukhan@gmail.com

Аналітична однолиста в $\mathbb{D}=\{z:|z|<1\}$ функція $f(z)=\sum_{n=0}^{\infty} f_{n} z^{n}$ називається опуклою, якщо $f(\mathbb{D})$ - опукла область, і називається близькою до опуклої, якщо існуе така опукла в $\mathbb{D}$ функція $\Phi$, що $\operatorname{Re}\left(f^{\prime}(z) / \Phi^{\prime}(z)\right)>0$ $(z \in \mathbb{D})$. Кожна близька до опуклої в $\mathbb{D}$ функція $f$ є однолистою в $\mathbb{D}$, і отже, $f^{\prime}(0) \neq 0$. Тому функція $f \in$ близькою до опуклої в $\mathbb{D}$ тоді і тільки тоді, коли функція $g(z)=z+\sum_{n=2}^{\infty} g_{n} z^{n}$ близька до опуклої в $\mathbb{D}$, де $g_{n}=f_{n} / f_{1}$. C.М. Шах визначив умови на дійсні параметри $\beta_{0}, \beta_{1}, \gamma_{0}, \gamma_{1}, \gamma_{2}$, за яких диференціальне рівняння $z^{2} w^{\prime \prime}+\left(\beta_{0} z^{2}+\beta_{1} z\right) w^{\prime}+\left(\gamma_{0} z^{2}+\gamma_{1} z+\gamma_{2}\right) w=0$ має цілі розв'язки, які разом зі своїми похідними близькі до опуклих в $\mathbb{D}$ функціями. Багато авторів продовжили ці дослідження. Тут розглядається неоднорідне рівняння Шаха $z^{2} w^{\prime \prime}+\left(\beta_{0} z^{2}+\beta_{1} z\right) w^{\prime}+\left(\gamma_{0} z^{2}+\gamma_{1} z+\gamma_{2}\right) w=$ $=\alpha_{0} z^{2}+\alpha_{1} z+\alpha_{2}$ з дійсними параметрами і вивчається існування близьких до опуклих його многочленних розв'язків. Неважко довести, що для того, щоб многочлен $f(z)=\sum_{n=0}^{p} f_{n} z^{n},(\operatorname{deg} f=p \geq 2)$ був розв'язком цього рівняння, необхідно, щоб $\gamma_{0}=p \beta_{0}+\gamma_{1}=0$. Основні такі резултати:

1) якщо $p \geq 3, \gamma_{0}=p \beta_{0}+\gamma_{1}=0, \beta_{1}+\gamma_{2} \neq 0, \alpha_{1} \gamma_{2}+p \beta_{0} \alpha_{2} \neq 0, \beta_{0}>0$, $2+\beta_{1}>0$

$$
0<\frac{(p-1) \beta_{0}\left(\alpha_{1} \gamma_{2}+p \beta_{0} \alpha_{2}\right)+\alpha_{0} \gamma_{2}\left(\beta_{1}+\gamma_{2}\right)}{\left(\gamma_{2} \alpha_{1}+p \beta_{0} \alpha_{2}\right)\left(2+2 \beta_{1}+\gamma_{2}\right)} \leq \frac{1}{2}
$$

і або $\gamma_{2}>0$ та $(p-2) \beta_{0} \leq 2+\beta_{1}$, або $-3\left(2+\beta_{1}\right)<\gamma_{2}<0$ та $3(p-2) \beta_{0} \leq$ $\leq 3\left(2+\beta_{1}\right)+\gamma_{2}$, то неоднорідне рівняння Шаха має многочленний розв'язок $f(z)=\frac{\alpha_{2}}{\gamma_{2}}+\frac{\alpha_{1} \gamma_{2}+p \beta_{0} \alpha_{2}}{\gamma_{2}\left(\beta_{1}+\gamma_{2}\right)} z+\frac{(p-1) \beta_{0}\left(\alpha_{1} \gamma_{2}+p \beta_{0} \alpha_{2}\right)+\alpha_{0} \gamma_{2}\left(\beta_{1}+\gamma_{2}\right)}{\gamma_{2}\left(\beta_{1}+\gamma_{2}\right)\left(2+2 \beta_{1}+\gamma_{2}\right)} z^{2}+$ $+\sum_{n=3}^{p} f_{n} z^{n}$, де $f_{n}=\frac{(p-n+1) \beta_{0}}{n\left(n+\beta_{1}-1\right)+\gamma_{2}} f_{n-1}$ для $3 \leq n \leq p$, який разом 3 усіма своїми похідними $f^{(j)}(1 \leq j \leq p-1)$, близькими до опуклих в $\mathbb{D}$ 
функціями;

2) якщо $p \geq 3, \gamma_{2} \neq 0, \gamma_{0}=p \beta_{0}+\gamma_{1}=\beta_{1}+\gamma_{2}=\alpha_{1} \gamma_{2}+p \beta_{0} \alpha_{2}=0$, $\beta_{0}>0,2+\beta_{1}>0,3(p-2) \beta_{0} \leq 2\left(3+\beta_{1}\right)$ i $0<\frac{\alpha_{0}+(p-1) \beta_{0}}{2+\beta_{1}} \leq \frac{1}{2}$, то неоднорідне рівняння Шаха має многочленний розв'язок $f(z)=\frac{\alpha_{2}}{\gamma_{2}}+z+$ $+\frac{\alpha_{0}+(p-1) \beta_{0}}{2+\beta_{1}} z^{2}+\sum_{n=3}^{p} f_{n} z^{n}$, де $f_{n}=\frac{(p-n+1) \beta_{0}}{(n-1)\left(n+\beta_{1}\right)} f_{n-1}$ для $3 \leq n \leq p$, який разом з усіма своїми похідними $f^{(j)}(1 \leq j \leq p-1)$ близькими до опуклих в $\mathbb{D}$ функціями;

3) якщо $p \geq 3, \gamma_{2}=\alpha_{2}=\gamma_{0}=\gamma_{1}+p \beta_{0}=0, \beta_{1} \neq 0, \alpha_{1} \neq 0, \beta_{0}>0,2+\beta_{1}>0$, $(p-2) \beta_{0} \leq 2+\beta_{1}$ і $0<\frac{(p-1) \beta_{0} \alpha_{1}+\alpha_{0} \beta_{1}}{\alpha_{1}\left(1+\beta_{1}\right)} \leq 1$, то неоднорідне рівняння Шаха має многочленний розв'язок $f(z)=\frac{\alpha_{1}}{\beta_{1}} z+\frac{(p-1) \beta_{0} \alpha_{1}+\beta_{1} \alpha_{0}}{2 \beta_{1}\left(1+\beta_{1}\right)} z^{2}+$ $+\sum_{n=3}^{p} f_{n} z^{n}$, де $f_{n}=\frac{(p-n+1) \beta_{0}}{n\left(n+\beta_{1}-1\right)} f_{n-1}$ для $3 \leq n \leq p$, який разом з усіма своїми похідними $f^{(j)}(1 \leq j \leq p-1)$ близькими до опуклих в $\mathbb{D}$ функціями; 4) якщо $p \geq 3, \gamma_{2}=\alpha_{2}=\gamma_{0}=\gamma_{1}+p \beta_{0}=\beta_{1}=\alpha_{1}=0,(p-2) \beta_{0} \leq 2 \mathrm{i}$ $0<\alpha_{0}+(p-1) \beta_{0} \leq 1$, то неоднорідне рівняння Шаха має многочленний розв'язок $f(z)=z+\frac{(p-1) \beta_{0}+\alpha_{0}}{2} z^{2}+\sum_{n=3}^{p} f_{n} z^{n}$, де $f_{n}=\frac{(p-n+1) \beta_{0}}{n(n-1)} f_{n-1}$ для $3 \leq n \leq p$, який разом з усіма своїми похідними $f^{(j)}(1 \leq j \leq p-1)$ близькими до опуклих в $\mathbb{D}$ функціями.

Ключові слова: лінійне неоднорідне диференціальне рівняння другого порядку, многочленні коефіцієнти, многочленний розв'язок, близька до опуклої функція. 